\title{
THE ESSENCE OF THE TEXT UNITS
}

\author{
Amanov Abdijabbor Sattarovich \\ Senior Teacher, Department Of Uzbek Language and Literature, Namangan State University, \\ Namangan, Uzbekistan
}

Article DOI: $\underline{\text { https://doi.org/10.36713/epra5432 }}$

\begin{abstract}
This article discusses the essence of the text concept in today's Uzbek linguistics. It also provides an overview of the text in the world linguistic and different approaches to this event.

KEYWORDS: the theory of the text, linguistic of the text, the ontological and functional signs of the text, the semantic structure of the text, the syntactic integrity, the syntactic structure, paragraph, maximum text, minimal text.
\end{abstract}

\section{INTRODUCTION}

In physics, the discovery of the atom was considered a great success, and shortly after it was announced as the smallest particle, it became known to the world of science that the atom, in turn, would also be divided into fragments. We are confident that scientific research in this area will reveal that even the smallest fractions can be divided. Because an objective being is a collection of particles that can be divided into infinite parts.

XX century scientific thought, Hegelian dialectics and dialectical categories proved that the most important concepts of existence and social life are inextricably linked. This, in turn, had a profound effect on the development of all the humanitarian sciences. Now it is necessary to imagine and investigate each event in a general connection, that is, in a certain chain. The most important and complex linguistic relationship between human society since its inception. It is of great practical and theoretical importance to study them, or rather to study the texts that reflect the essence of those relations, to analyze the rules of their formation. The reforms taking place in our lives are reflected in every field, including linguistics, which today has made great strides in all areas of language. The emergence of a number of new directions in language (computer linguistics, psycholinguistics, mathematical linguistics, sociolinguistics) and the scale of scientific research created in connection with their study is also evidence of this.

In particular, text linguistics is one of the new directions in the field of linguistics. Philology and other humanitarian sciences can be considered as a set of knowledge about the text, which includes examples of culture, language and literature of the peoples. Nevertheless, when interpreting the concept of the text, linguists express different opinions.

\section{LITERATURE REVIEW}

Studies devoted to the study of the text and its nature appeared at the end of the twentieth century. Text linguistics is one of the issues that has attracted the attention of many linguists. In particular, in world linguistics V. Matezius, I. Galperin, L.Loseva, O. Moskalskaya, K. Abdullaev, in Uzbek linguistics in this regard R. Kungurov, I. Kochkortoyev, Q. Samadov, N. Mahmudov, M. Yoldoshev, X. Doniyorov, E. Kilıchev, S. Karimov, B. Umarkulov expressed their opinion about the text. In the general development of text theory, text linguistics, the services of representatives of the Prague Linguistic Circle, German, French, English, American, Dutch, Polish and other schools of linguistics are recognized in world linguistics, while in Russian linguistics the works of V.V. Odinsov, I. R. Galperin, O. I. Moskalskaya, L. M. Loseva, Z.Y. Turaeva, N. S. Valgina, N. D. Zarubina deserve special attention. 


\section{EPRA International Journal of Research and Development (IJRD)}

Academician G. Abdurahmanov was one of the first in Uzbek linguistics to deliver a speech on the theory of text at the third Conference of Turkologists of the former Soviet Union in Tashkent in 1980, expressed his views on the essence and solutions of the problem, distinguished a number of types of text. Linguist A. Gulamov also expressed his views on the essence of the text.

In the later period of Uzbek linguistics, it is possible to note the works of such scholars as A. Mamajonov, M. Tukhsonov, M. Abdupattoyev, N. Turniyozov, M. Khakimov in this field [1]. Text linguistics has been formed as a separate branch of linguistics, is constantly developing, and new theoretical generalizations are being made. First of all, it should be noted that there are different opinions among experts in the definition of the concept of text.

\section{RESULTS AND DISCUSSION}

Some linguists consider only a written whole or a piece of speech to be text. For example, the Russian linguist L.M. Loseva emphasizes that the definition of "text" should be based on the characteristics of all texts [2]. I. R. Galperin, who studied the text as an object of linguistic research, emphasizes that "completion is realized in the form of a written document as one of the leading aspects of the text that reflects its ontological and functional features". In his view, a text is a speech work in the form of writing. However, most linguists who deal with the problems of text linguistics point out that text can be both written and oral [3].

Indeed, the same idea has a scientific and logical basis, and it accurately reflects the essence of the text. Z.Y. Turaeva states that according to the general theory of textual linguistics, it is possible to take a text that is the product of oral or written speech as its subject, but it is expedient to interpret the text in a narrow sense, that is, only as a product of written speech. R.A. Karimova, who studied the semantic-structural structure of the text on the example of oral and written speech in Russian, noted that the text is a work of speech not only graphically, but also orally, in which the oral form is the genetic basis and the analysis of the facts leads to the theoretical conclusion that "at first glance the text seems to be located at opposite points of space, the verbal emergency (spontaneous) text and the written text (literary text) have a common feature - a certain structure." [4]. In linguistics, in almost all of the many and varied definitions given to a text, the sign of coherence and integrity is expressed in one way or another.

A. Gulamov emphasizes that the completeness of the idea is relative, the completeness of the content of the work can be understood from the whole text, citing the example of a unified text consisting of three paragraphs, and based on this, he mentioned:

- "Expression is not limited to the sentence (simple sentence and compound sentence). A complete idea is usually given by a syntactic integrity that is larger than the sentence. Speech is a component of this integrity.

- This component is connected with other components of the same integrity in various ways (content, grammar) by various means. It has its own composition and stylistic features.

- A simple sentence can be a paragraph in its integrity under certain conditions.

- Such a syntactic integrity is a syntactic construction text. Some sentences express a relatively complete idea, while the text expresses the content of an entire complex.

- Because the text is a whole, it may have some headings that match its content. The text is divided into separate segments parts, paragraphs, sentences. Thus, the text makes it even clearer that language is a means of communication. Speech is reflected in the composition of the text.

A text is a large piece of speech, and a paragraph is a piece of text. All versions of the text (maximum text and minimum text) completely represent a particular topic (content). So it is a highlevel syntactic unit. [5] Given these features of the text, some researchers consider it necessary to distinguish it as an independent branch of linguistics (with names such as grammar of a text $r$, text linguistics). Some call it text syntax (such as phrase syntax, simple sentence syntax) as a continuation of sentence syntax, thereby expanding the meaning of the syntax term to a larger syntactic integrity than the sentence as the basic syntactic unit. In this case, the upper limit of the syntax is the text syntax, not the compound sentence syntax. M. Tukhsonov studied the system of means connecting elements in the Uzbek language with the difference of macrotext and mikrotext in his dissertation[6].

One of the first generalized, educational works on text linguistics in Uzbek linguistics was created by A. Mamajonov. His special course for students of philology "Text Linguistics" analyzes scientific views on the text. Issues such as the essence, types and units of the concept of text, the connection and means of connection of these units, synonymy between text units, syntactic and stylistic figures are described. [7] Later, in the book "Syntax of Text", published in collaboration with his student M. Abdupattoev, the structural-semantic and stylistic aspects of the text, the thematic-rhetorical 


\section{EPRA International Journal of Research and Development (IJRD)}

relationship in the text units were analyzed in detail, the relevant conclusions were summarized [8].

N.Turniyozov's book "Text Linguistics" is one of such educational works, which includes general information about the text in accordance with the relevant curriculum, the concepts of micro and macrotext [9]. M. Khakimov is another Uzbek linguist who is concerned with text problems. In his dissertation, "Contribute to the work aimed at identifying the specific links and functions of the scientific text and its units, the definition of the author's personal relationship and its types in the scientific text", he studied in detail the syntagmatic and pragmatic features of the Uzbek scientific text on the basis of rich factual materials [10].

A number of scientific articles have been published in Uzbek linguistics related to the study of this or that aspect of the text. To date, more than twenty methods of studying the text have been developed and are widely used in linguistics. One of them is the statistical study of Uzbek texts. This method of studying the text is consistently expressed in M. Yuldashev's paper " Linguopoetic study of literary text", which includes methods, views, frequency vocabulary of studying texts of different functional styles on the basis of statistical methods [11].

The analysis and application of linguistic-statistical methods of text study is also one of the current problems of text linguistics. The researches of Samarkand scientists S. Karimov, M. Yuldashev, D. Urinbaeva are noteworthy in this regard. In linguistics, the psycholinguistic study of the text also has a specific history. Especially researches of linguists I. Lisakova, A.A. Leontyev, N.S. Evchik, A. Shtern, T.A. Drozdova are remarkable. The work in this area deals with the processes involved in the creation and comprehension (perception) of text, the relationship between human psychology and the ability to create text [12].

Works in the psycholinguistic study are also emerging in Uzbek linguistics. In particular, I. Azimova's dissertation provides an overview of the general views on the semantic perception of the text in psycholinguistics, studies the linguistic and extralinguistic factors influencing the comprehension of the text on the basis of psycholinguistic experiments, shows the levels of the text comprehension process [13].

Another important branch of text linguistics, the "direction of the study of literary text", can be said to be highly developed in Uzbek linguistics. In this direction, M. Yuldashev defended his doctoral dissertation on the "Linguopoetic study of literary text". In this doctoral dissertation, the expression of the aesthetic function of language in the literary text is analyzed on the example of the best works of
Uzbek literature. The semantic types of the literary text and the problem of intertextuality are classified and described on the basis of factual materials, the principles of linguopoetic analysis of the literary text are developed. The style of formation of the literary text and the linguistic factors involved in it are studied, as well as the mechanisms of poetic actualization of phonographic, lexical, morphological and syntactic means in the literary text [11]. S. Boymirzayeva's doctoral dissertation is devoted to the monographic study of the cognitive nature of the semantic structure of the text phenomenon. The work explores the communicative-pragmatic features of the text phenomenon, shows the integral connection of the categories of modality and temporality with the essence of the text, which serve to form its content. It is also revealed that the formation of the content of the text is a social phenomenon, it is a product of linguistic cognitive activity with the participation of the author and the recipient [14].

Sh.Turniyazova's dissertation is devoted to the study of derivational features of text formation, which discusses the microtext and its types, proving that even a simple grapheme (sound in speech), words and phrases can come in the form of text. This paper provides a scientific interpretation of the derivational properties of micro and macro texts, and describes the derivational properties of text components and general text structure. It also discusses the semantic factor as a derivation operator, as well as lexical devices and the hierarchical relationship of text components [15].

\section{CONCLUSION}

The reforms taking place in our lives are reflected in every field, including linguistics, which today has made great strides in all areas of language. The emergence of a number of new directions in language (computer linguistics, psycholinguistics, mathematical linguistics, sociolinguistics) and the scale of scientific research created in connection with their study is also evidence of this. In particular, text linguistics is one of the new directions in the field of linguistics. Philology and other humanitarian sciences can be considered as a set of knowledge about the text, which includes examples of culture, language and literature of the peoples. Nevertheless, when interpreting the concept of the text, linguists express different opinions. Nowadays, a classification of particle constructions according to their occurrence has also been developed, and particle constructions have been described grammatically and linguo-poetically. Given this, it can be said that research in the field of text linguistics is being conducted in various directions and aspects. There is no doubt that new areas of text research will be discovered in the future. 


\section{REFERENCES}

1. Mamajonov A. (1989). "Linguistics of text". Tashkent. pp. 10-12.

2. Loseva L. M. (1980). "How the text is constructed?". Moscow. pp. 25.

3. Galperin I. R. (1981). "Text as an object of linguistic research”. Moscow. pp. 36-37.

1. 4.Tukhsanov M. (1990). "Microtext and its communicative integrity". Tashkent. pp. 87.

4. Karimova R.A. (1992). "Semantically structural organization of the text (based on oral spontaneous and written texts)". Moscow. pp. 27.

5. Gulomov A., Askarova M. (1987). "Modern Uzbek literary language. Syntax". Tashkent: pp. 6-7.

6. Tukhsanov M. (1987). "Microtext and the system of expression of its coeness in Uzbek literary speech”. Tashkent. pp. 24.

7. Mamajonov A. (1989). "Linguistics of text". Tashkent.pp. 31.

8. Mamajonov A., Abdupattoyev M. (2002). "Text syntax".Fergana. pp. 42-43.

9. Turniyozov N. (2004). "Text linguistics". Samarkand. pp. 11.

10. Khakimov M. (2001). "Pragmatic interpretation of the text in Uzbek language" Tashkent. pp. 1617.

11. Yuldashev M. (2009). "Linguopoetic study of literary text". Tashkent, pp. 3.

12. Lisakova I. P. (1981). "Language of the newspaper: socio-psycholinguistic aspect". Moscow. pp. 17.

13. Azimova I. (2008). "Psycholinguistic study of the semantic concept of newspaper texts in Uzbek". Tashkent. pp. 14-15.

14. Boymirzayeva S. (2010). "Categories that form the communicative-pragmatic content of the text in the Uzbek language". Tashkent. pp. 21.

2. 15.Turniyazova Sh. (2010). "Derivative features of text formation in modern Uzbek language". Tashkent. pp. 56-57. 